\title{
The Median Sternotomy: The Unkindest Cut of All? Pearls, Pitfalls, Aphorisms, \& Myths
}

\author{
Curt Tribble, MD, ${ }^{1}$ Walter Merrill, MD,${ }^{2}$ Stephen Derryberry, $\mathrm{MD},{ }^{3}$ Gene Parrino, $\mathrm{MD}^{4}$ \\ ${ }^{1}$ Division of Cardiac Surgery, University of Virginia, Charlottesville, VA, USA; ${ }^{2}$ Department of Cardiothoracic Surgery, Vanderbilt \\ University, Nashville, TN, USA; ${ }^{3}$ Mercy Hospital, Youngstown OH, USA; ${ }^{4}$ Department of Cardiothoracic Surgery, Ochsner Medical \\ Center, New Orleans, LA, USA
}

The patient's outcome correlates directly with the surgeon's attention to a myriad of minor details. This obsession with doing a lot of little things right is the foundation for good results. — Hiram C. Polk

\section{INTRODUCTION}

Please Don't Let Me Be Misunderstood. _Eric Burdon and The Animals

While some have claimed that a median sternotomy is an 'unkind cut,' when this incision is performed, closed, and managed optimally, it can be one of the 'most kind cuts' used for major operations. The median sternotomy is the most commonly used incision for coronary artery bypass surgery, which is the most common operation performed in the United States at the current time. This approach is, of course, used for many other cardiac and thoracic operations, as well. It is, however, also one of the most misunderstood procedures in Surgery. Because it is an incision that even a novice surgical resident can perform, with proper supervision, the subtleties and nuances of not only opening but also of closing sternotomies are not often conveyed optimally to our trainees. In this treatise we will attempt to comprehensively address these subtleties, nuances, and misunderstandings, both for the benefit of our younger learners, but also, and more importantly, for the benefit of our patients. Risk
Buffett

This treatise, and its length, deserves a bit of an explanation or, even an apology, which is that there are many things in Surgery that seem simple, once you know how to do them. However, there are many technical aspects of surgical operations that, at least once, deserve a 'quiet hearing' with a full description of, and explanation for, the subtleties and nuances of the optimal way to do that procedure.

Correspondence: Curt Tribble, MD, Professor of Cardiothoracic Surgery, University of Virginia Health System, Division of Cardiac Surgery, Box 800679, Charlottesville, VA 22908; 434-243-9250 (e-mail: ctribble@virginia.edu).
In the very first day of my own Thoracic Surgery residency, my attending said "let me show you how to close a sternotomy, because after today, you'll be on your own." By the next day, the closure was unstable, and my chief resident was assigned to help me reclose this patient. As he came in the room to start the case, he said "Never let an attending close the chest." He proceeded to show me the correct way to close a sternotomy, and that strategy is the one that I have used on every sternotomy I have done, or supervised, in the ensuing thirty years of my practice. I later came to realize that the strategy for closing the sternum described here likely originated at the Surgery Branch of The National Heart, Lung, and Blood Institute (NHLBI) of the National Institutes of Health (NIH).

\section{Fast is fine, but accuracy is everything. - Wyatt Earp}

As is true in all surgical operations, all of the details matter, and nothing is neutral. However, it is amazing how little is written about creating and closing a median sternotomy incision in the most popular textbooks in our discipline. In fact, I reviewed four major textbooks of cardiothoracic surgery, as well as three of the most popular techniques books of cardiac surgery, and the details of median sternotomy techniques bordered on being non-existent. This very important information seems to fall clearly in 'the hidden curriculum,' which is the impetus for this review.

Therefore, we will cover in detail the crucial concepts of opening and closing a standard median sternotomy in this treatise. We will not attempt to address unusual situations like pectus excavatum nor the so-called less invasive sternal incisions. We will also not cover reoperative cardiac surgery, as that topic has been covered in a separate treatise. [Tribble, Reoperative Cardiac Surgery: Parts I \& II, 2018] Finally, while this essay does address important ways to minimize the risk of mediastinitis, the most devastating consequence of a median sternotomy 'gone bad,' we will not address the care of patients with mediastinitis, a topic which we will address at a later time.

\section{A BRIEF HISTORY OF THE MEDIAN STERNOTOMY}

The median sternotomy is thought to have been first proposed by Milton in 1897, but this approach to the chest was 
not widely used until Julian and colleagues reintroduced it as the optimal incision for cardiac operations in 1957. [Julian 1957, Dalton 1992] It is currently one of the most commonly performed major incisions used in cardiac surgical operations in much of the developed world.

\section{PREOPERATIVE PREPARATION OF A PATIENT FOR A MEDIAN STERNOTOMY}

There are a number of issues to be considered for a patient who is to undergo a median sternotomy, including managing medical issues such as perioperative antibiotic regimens, diabetes, and reducing the individual patient's bacterial colonization. Because these issues are relatively well agreed upon, we will not cover them in detail here. [Edwards, 2006 \& Hong, 2018]

\section{THE GERM THEORY: PREPPING THE PATIENT IN THE OPERATING ROOM FOR A MEDIAN STERNOTOMY}

One of my favorite scrub nurses once said to me while I was prepping and draping a patient, "You are so fastidious and detail oriented that I'll bet you are very hard to live with!" I responded, "Who would you want doing your operation? Someone like me or a slob?" She quickly admitted "I'd want someone like you to do my operation, but I still wouldn't want to live with you." I had to laugh out loud, of course.

One must start with a firm belief in and commitment to understanding 'the germ theory.' Obviously, the operating room environment must be carefully monitored and controlled to minimize the risk of airborne contamination of the operative field. Most surgical teams develop a system for their operations and insist on a 'same way every day' philosophy. The goals of the process of prepping and draping include creating a:

- Sterile field

- Reasonable work space for the planned procedure

- Set up that will protect the operating team members from exposure to body fluids and from injury

To prepare a patient for a sternotomy, there are several issues to consider. The first issue is that patients should have body hair clipped and not shaved. And, the amount of hair to be removed should be minimized, as even clipping can irritate the skin. This clipping should not occur in the operating room, as hair particles can float around the room for a while after clipping. Other preoperative considerations include having patients shower or bathe, the choice and timing of preoperative prophylactic antibiotics, and many other preoperative strategies, which will not be addressed in depth here. [Lazar, 2009]

One must also be sure that all necessary tubes and devices have been inserted, placed, or attached. A specific issue to consider at this point is whether external defibrillator pads should be placed. These pads should always be placed when the patient has had a prior sternotomy, as it will, obviously, be quite some time before the heart can be dissected out enough to use internal paddles. Relatively early in my career, I concluded that I would use these external defibrillator pads on all cases, both because I am inclined towards a 'same way every day' mentality and because there will be the occasional patient who fibrillates prior to having had their chest opened. There are a few other things to consider prior to prepping, including positioning of the operating room lights, applying antibiotic or antiseptic to the patient's nares, and, possibly, marking the patient's femoral pulses, especially if it is anticipated that femoral cannulation or, later, that an intra-aortic balloon pump might be needed.

The next step is the application of the skin prep solution. Many surgeons like to begin the prep with alcohol, to 'degrease' the skin. Most agree that chlorhexidine gluconate (Hibiclens) is a reasonable choice for the prep solution, while povidoneiodine (Betadine) is likely not quite as good. This prep solution should be applied widely, well beyond the expected operative field, which is basically from chin to toes, at least to the mid axillary line, side to side on the torso, and circumferentially for the legs. Many recommend that those involved in prepping and draping the patient be gowned and gloved, which may reduce the possibility of contamination of the field which can be caused by 'shedding' from the arms and clothing.

It is optimal to have some kind of structure to hold the towels and drapes off of the patient's face. Many years ago, we had a local craftsman construct a special structure, made of aluminum, that we call 'the airplane.' This device has wide wings to allow drapes to hang on them while creating a wide space for working on the upper chest. And, the structure has a flat surface that sits over the patient's head and provides a good platform for placing instruments, the defibrillator paddles, pacing wires, and the occasional instrument, as well as a good surface on which an assistant can prop an arm when necessary. There are, of course, many devices that can serve a similar function.

\section{DRAPING THE PATIENT FOR A STERNOTOMY: CREATING AND MAINTAINING A STERILE FIELD}

If the patient is to have vein harvested for the operation (or if there is even a possibility that vein might be needed), the legs must be prepped. Usually this prep is applied circumferentially from the toes to the groins, and many will have someone hold the feet up as this prep is applied. Stockinets are often placed when this prep has been accomplished, and, with the legs still in the air, two layers of sterile drapes are positioned under the legs. At that point, the legs can be lowered onto these drapes. Many surgeons prep the legs in this way for all cases, invoking the possibility that vein might be unexpectedly needed, even in a case in which a coronary bypass is not planned.

The next consideration is draping the patient. The first step in draping the patient is the placement of sterile towels, starting with the groin. The towel used in this position needs to be pulled into as narrow a strip as will cover the vital areas, with a focus on the potential need to access the 
femoral vessels. The next towel to place is the one that will lie over the neck. The inferior edge of this towel should lie well above the sternal notch, as you don't want to have the edge of this towel become detached from the skin of the neck when you're working near the most superior part of your field. This towel can be folded so that it does not interfere with the anesthesiologist's ability to manage the airway. I like to wad up two towels and place them just above the shoulders on either side of the lower neck. Then, towels can be placed along the sides of the patient, leaving adequate room for the chest tubes that will eventually be placed. If any of these towels end up being placed further from the required operative field than seems optimal, you can, of course, place a second towel on top of the first, with its edge closer to the desired position.

Once the towels have been positioned, a 'sticky' drape is applied to the chest. It is important to pull the paper backing off the drape to a considerable degree so that the drape can be placed straight down on the chest. This maneuver is important because if the sticky drape is placed down on one side and then pulled to the other side it may distort the skin, which can result in the skin incision not being optimally aligned in the midline. While this may seem to be merely a cosmetic issue, patients will most definitely be annoyed if their chest incision is not straight. After all, they may not be able to help wondering how well you did their operation if the skin incision isn't even in the exact midline of their chest, and who could blame them for thinking such things? As a patient once said to me: "I guess I should be happy to have a big 'S' on my chest. I decided to tell my friends it's because I'm Superman." Still, at the end of the day, the only thing the patient and their family can actually see of our handiwork is that skin incision. We need to get it right!

The paper drapes are then applied, after the surgical team is gowned and gloved, with care taken to maintain a field optimized for the planned operation. It is worth noting that there is value in making sure that the drapes are symmetrical, which will help in making the skin incision in the midline. Those who are placing these drapes should have on an extra pair of gloves which will allow changing the outer pair, should there be any suspicion that someone has touched something that is not sterile during the draping that would contaminate those gloves. Sometimes it will be helpful to have extra pieces of a sticky drape available to tack down folds of the drapes or to help the drapes adhere in an optimal configuration. My favorite drapes are those usually used for laparoscopic cases because they have plastic pockets along the sides, which are useful for storing things needed during the operation, such as pacing cables, and are also useful for keeping fluids or blood from running off the table and getting on the floor or on your shoes.

Once all the drapes have been positioned and secured, the instruments and gear needed for the operation can be positioned, including cautery, defibrillator paddles, and, eventually the tubing for the cardiopulmonary bypass circuit. Once the operative field has been properly set up, a time out is conducted, using a script or checklist, with all members of the operative team members participating. Once the checklist has been reviewed, it is optimal to name everyone in the room, preferably by their first names. [Tribble \& Merrill, 2014]

At this point, you are ready to start the operation. One other general principle may be worth announcing to your team, which is that no one should move from working on the legs or the groins to working in the chest, without changing at least their outer gloves and, preferably, their gowns.

\section{PREPARING FOR THE STERNOTOMY: OPENING THE SOFT TISSUES}

The first step of making the incision is to mark the midline, after draping has been completed and all the necessary gear has been organized on the field. Some like to use a marker to mark the intended site of the incision, while others will use a heavy suture, pressed into the site planned for the incision, leaving a dent that can be followed as the skin incision is made.

Obviously, the landmarks for the incision must be identified. Doing so is important because the drapes may not always have been placed symmetrically. Finding the midline at the superior end of the sternum is relatively easy, in that it should lie in the middle of the sternal notch. (It is worth noting again that the upper drape should be placed high enough on the neck so that the sternal notch is easily visible and can be palpated.) Finding the midline at the inferior end of the planned incision can be more challenging, particularly because the tip of the xiphoid, if palpable, may not be a reliable landmark, in that it may lie to one side or the other of the midline. However the arch of the rib cage is a reliable way to determine the midline in that area, if the tip of the xiphoid is not palpable or if its tip seems to be off center.

The initial incision is made with a scalpel, cutting through the drape and into the epidermis. The incision is usually continued from that point with the Bovie electrocautery. While some purists believe that healing is improved when the Bovie is avoided or minimized, many believe that it does not significantly impair wound healing, while it does, of course provide better hemostasis. Furthermore, some have noted that the use of the Bovie may transiently 'stun' the nearby sensory nerve fibers which might reduce postoperative pain at the incision site to some degree.

The alignment of the incision with the midline should be continuously re-evaluated, by feeling the landmarks, especially, as the incision is deepened into the fascia of the anterior chest wall and the periosteum, particularly by feeling the interspaces between the ribs at the edge of the sternum. Usually, it is best to mark the midline (or the precise line intended for the planned sternotomy) repeatedly, with short applications of the Bovie, using these landmarks. Eventually, the incision is completed by cutting into the periosteum of the anterior sternum, from the sternal notch down to the tip of the xiphoid, and the incision is carried down into the midline of the upper abdominal fascia, while avoiding, when possible, entry into the peritoneum, which will lie beneath the properitoneal fat. If the peritoneum is opened inadvertently, you should consider closing it, as doing so will prevent 
blood or other fluid from entering the peritoneum during the planned operation.

One technique to be considered at this point is whether or not you want the sternotomy to be precisely in the midline of the sternum, from bottom to top. Many surgeons advocate making the incision in the sternum itself be a bit less than straight, with the concept being that a slight curve in the sternotomy will 'force' the sternum to stay aligned optimally when closed. This concept may be appealing to those who are familiar with the principles of carpentry, especially those familiar with cabinet making, but may be 'a bridge too far' for the less experienced trainee. [Lee 1984, Williams 2000] If a slight curve is to be incorporated into the sternotomy, one must incise (or 'mark') the periosteum with the Bovie with the intended line, when preparing to saw the sternum. Also, if this technique is used, the slight curve can be limited to the manubrium, especially in patients whose sternum is narrow, given that it is always wider than the lower portion of the sternum.
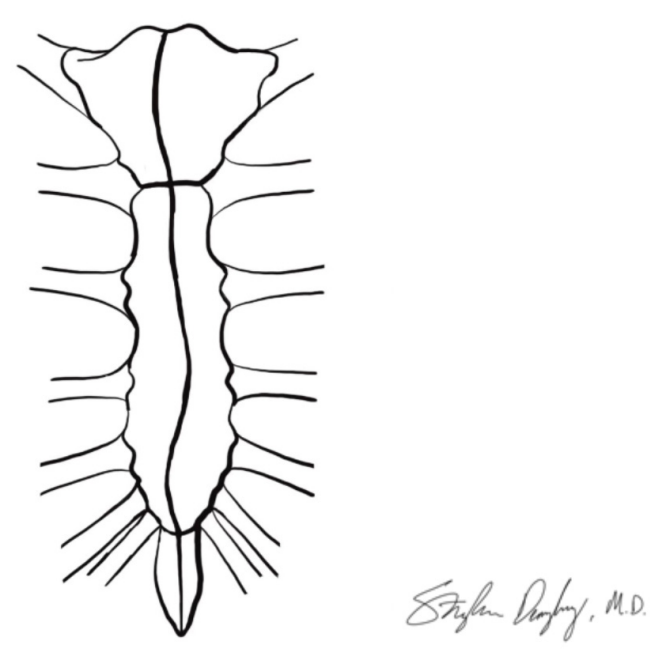

At this point, attention can be turned to cutting into the thin fascia of the neck just above the sternal notch. As the sternal notch is progressively exposed, one must be mindful of the vein that often crosses the midline in this area. If this vein is visualized, it can sometimes be clipped and divided, remembering to avoid applying the electrocautery directly onto the metal clips, as doing so can weaken the tissue in the clips, which might lead to the dislodgement of the clips at some later, usually inopportune, time.

The next step is to free up the soft tissue between the upper abdominal fascia and the xiphoid, where you may find another vein crossing the midline. This vein is often so adherent to the xiphoid that it cannot be clipped or tied. Therefore, it will sometimes need to be grasped with forceps to which the electrocautery is applied. Occasionally, if the xiphoid is not too calcified, it can be divided with the electrocautery up to the lower edge of the sternum in the midline. Sometimes the xiphoid needs to be cut with heavy scissors. Occasionally, it will seem like the better part of valor to actually remove the xiphoid, particularly if it is prominent and angled anteriorly.
Next, curved scissors, such as Metzenbaum scissors, will need to be held with the curve pointing anteriorly and passed beneath the inferior edge of the sternum, in the midline, to create a small space in the diaphragmatic attachments in this area so that one can insert an index finger into the space to begin to sweep the pleura and soft tissues away from the sternum and to each side. This maneuver should help prevent opening of the pleura or, heaven forbid, the pericardium, when it comes time to use the sternal saw to open the sternum. It is also useful to insert a finger into the space behind the manubrium, in a similar manner, prior to doing the sternotomy.

\section{PERFORMING THE ACTUAL STERNOTOMY}

When all of these maneuvers are completed, it is time to divide the sternum with the sternal saw. Some surgeons like to saw from the top down, invoking another principle of carpentry, which is that it may be easier, and more controlled, to be pulling a cutting instrument towards yourself than it is to be pushing that instrument away from you. I, however, have never really bought into that concept, though it is truly 'dealer's choice.' When the saw is on the field and properly set up, it is tested to be sure that the blade seems to be moving freely. It is at this point that the surgeon should ask that ventilation be held, not only to keep the lungs themselves from being injured but also to allow the heart and mediastinal contents to 'fall away' from the anterior chest wall and the midline. I have found that the desired effect of taking the pressure off the lungs is optimally achieved when the endotracheal tube is completely disconnected from the ventilator tubing. One other maneuver that can help avoid 'drawing' the soft tissues of the mediastinum into the midline is to start the sternal incision with the saw, stop sawing about a quarter of the way up, and withdrawing the saw. Some believe that this subtle maneuver further lessens the chance that the pleura will be opened by the saw. After all, one need not be in a hurry to get the sternum opened quickly, as a well ventilated patient can go without ventilation for many minutes, if need be. Once the sternum has been opened with the saw, the surgeon should assure that ventilation is resumed.

At this point, the first priority is to assure that no injuries have occurred to the heart, the lungs, or the innominate vein. Next, attention needs to be turned to the edge of the back table to the sternum, which is usually bleeding, to at least some degree. This bleeding can generally be staunched with the use of electrocautery. In fact, there is an old saying that cardiac surgery could not have developed until the electrocautery had been invented, because without it, bleeding from these posterior edges of the sternum would quite often be challenging to control. The next place that attention needs to be focused is on the bone marrow of the sternum, which often needs some kind of hemostatic agent applied to it in order to minimize oozing which can be a nuisance in a long operation. We will not delve deeply into the options, and the controversies surrounding them, for dealing with the sternal marrow in this treatise, but suffice it to say that many strategies have been employed for this purpose, ranging from bone wax or a paste made with an antibiotic, such a vancomycin, to some sort 
of bone hemostatic agent such as Ostene, each of which have their advocates. [Lazar 2017, Vestergaard 2010, Wellisz 2008]

\section{MANAGING THE MEDIASTINAL CONTENTS AFTER THE STERNOTOMY}

The next step after completing the sternotomy is to insert a relatively small sternal retractor and to open the sternum a bit more to assure hemostasis and to examine the mediastinum more carefully to ensure that no unintended injuries have occurred. There is said to be some value to opening the sternum relatively gradually, if time permits.

The next step that should be taken is to dissect the properitoneal fat off the back of the upper abdominal midline fascia. This maneuver has the virtue of ensuring that tubes and wires can be passed later from the mediastinum to the upper abdominal area, with minimal chance of injuring the contents of the abdomen. After all, as the old saying goes, 'that ain't a good place for a colostomy' (nor for a gastrostomy). Furthermore, when this fat is dissected away from the fascia, closing this fascia accurately and appropriately at the end of the operation is considerably easier. This maneuver follows the old admonition of 'always open like you're gonna close.'

Next, particularly if an internal mammary artery is to be harvested, you must decide whether to open the pericardium at this point or later. There are a number of reasons to consider opening the pericardium at this point, including the following issues:

- If the patient were to become unstable, you will have ready access to the heart and aorta, for cannulation or, if necessary, defibrillation.

- You can examine the heart and aorta at that point, which could lead to changes in your operative plan. Some use Epiaortic ultrasound to examine the aorta more carefully to find the optimal site for cannulation.

- You can measure for graft lengths, if a coronary bypass is to be performed.

- You can create a 'Flege Flap' of pericardium and mediastinal fat which is an excellent way to cover the heart at the end of the operation. This technique has been previously described. [Flege, 1987, Tribble, 2017]

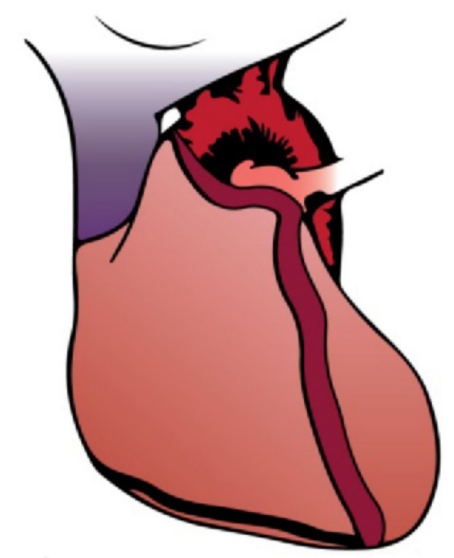

- You can also push the pleura off of the back of the chest wall, especially on the left, which has a number of virtues, including:

- Keeping the pleura intact, which protects the left lung and which lessens the amount of blood or fluid that can collect in the left pleural space during, and after, the procedure

- Removing the parietal pleura, thin though it may be, from the back of the left chest wall, which will facilitate taking down the left internal mammary artery (IMA) in a skeletonized manner.

- And, this maneuver allows the fat the lies posterior to the pleura and anterior to the pericardium to 'flop down,' which will help cover the heart, loosely but completely, at the end of the operation

- You can even consider placing cannulation sutures, which could facilitate going on bypass should the patient become unstable.

\section{CHOOSING AND PLACING RETRACTORS} AFTER THE STERNOTOMY

If the decision is made to open the pericardium at this point, rather than moving directly to taking down the IMA, you will need a larger sternal retractor. The retractor chosen should be long enough to have its blades rest on the inferior aspect of the sternal edges, because the sternotomy should always be opened in the configuration of an ' $\mathrm{A}$ ', rather than as an ' $\mathrm{H}$ ', because the lower area of the sternum, once opened, has much more flexibility than does the superior portion of the sternotomy. Careful placement and use of the sternal retractor will also reduce the chance of injury to the brachial plexus or first ribs. [Kalso, 2001] Some surgeons place their sternal retractors so that the ratchet mechanism lies over the upper abdomen, but I have never liked this arrangement because the retractor is in the way much of the time, especially when placing pacing wires and chest tubes.

If the IMA is to be taken down, a suitable retractor is positioned at this point, with some using the Rultract retractor (my own preference) and others using the Delacroix retractor (which is completely reasonable, as well). If the sternum is opened well and the preliminary dissection is completed prior to the placement of a Rultract mammary retractor, there is less of a tendency for the left side of the sternum to end up being higher than the right side of the sternum.

Once the IMA has been taken down, the sternum is prepared in a manner suitable for the rest of the case. Some surgeons will wrap the sternal edges with towels, hoping to minimize the risk of contamination, to soak up any blood that oozes from the marrow, and, possibly, to distribute the force of the retractor. I have never found that maneuver to be very helpful. Another strategy some surgeons have touted is to wrap the sternum with pump tubing that has been cut open on one side, especially if the sternum seems fragile as in the elderly, as this strategy may distribute the pressure of the blades of the retractor a bit, thus, protecting the sternum. [Khonsari, 2007] 


\section{PREPARING TO CLOSE THE STERNOTOMY}

After completing the planned operation and assuring hemodynamic stability, you need to examine each of the operative sites to ensure hemostasis, including the cannulation sites on the aorta and atrium, as well as the proximal and distal anastomoses, if a coronary bypass has been performed, or the aortotomy or atriotomy, if a valve operation has been performed. You must check the internal mammary bed if one or both of these arteries have been used for a coronary bypass. An adjunct to this phase of the operation is to irrigate the chest with warm saline, for several reasons, including washing out bone fragments, clot, tissue, or microorganisms. This maneuver will also, on occasion, reveal some bleeding that might not otherwise be apparent. It is also important to check both pleural spaces, if the pleura has been opened in any way. One caveat about aspirating the pleural spaces is that it is possible to injure the lungs with a sucker, especially if there are any adhesions between the lung and chest wall.

Generally pacing wires will have been placed prior to coming off bypass, but if they have not been attached at this point, you must at least consider whether or not they are needed. (My own practice has been to use both atrial and ventricular wires in virtually all cardiac operations). The pacing wire sites must also be looked at to assure that there is no bleeding associated with them. Chest tubes must be placed at, or prior to, this stage, as well. Utilizing a check list at this point can be helpful. [Loor, 2013]

This stage of the operation can also be a good time to get a preliminary count of needles, sponges, and instruments, since, as you move towards closing the sternotomy, you want to assure yourself that you are not leaving anything behind unintentionally. It will be considerably harder to look for of these things the further along you are in the process of closing the chest.

\section{PREVENTING ANY CONTACT BETWEEN THE RIGHT VENTRICLE AND THE STERNUM}

\author{
People seldom do what they believe in. They do what's conve- \\ nient, then repent. - Bob Dylan
}

Before closing the sternotomy you should cover the right ventricle, if at all possible, after the chest tubes and pacing wires have been positioned. The right ventricle and the back of the sternum should never, ever be allowed to touch each other. As the old saying goes, 'every patient is a reop, sooner or later.' The danger of reopening a sternum, at any point, comes largely from the right ventricle being adherent to the back of the sternum. As noted above, the approach I prefer to accomplish this goal is to cover the heart with the 'Flege Flap,' which is done by tacking the cut edge of the pericardium to the medial edge of the left sided pleural fat, using a few absorbable sutures. This maneuver will provide a loose covering of the heart, while positioning the actual pericardium beneath the midline.

Finally, this is the most appropriate point to place stitches in the upper abdominal fascia. These stitches should be interrupted figure of eight stitches with heavy absorbable suture material. This portion of the closure is extremely important and deserves your full attention. The first suture should be almost below the lowest edge of the opening, to assure optimal apposition of these fascial edges. The most superior of theses sutures should be placed at the bottom edge of the sternum. These sutures should be tagged with hemostats but not tied until later. To be absolutely clear, these sutures should never be placed after the sternum has been closed, because the visualization needed for proper placement of them is considerably better with the sternum at least somewhat open.

\section{CLOSING THE STERNOTOMY: PART I, HEAVY METAL}

When hemodynamic stability and hemostasis have been assured, all tubes and wires have been placed, the right ventricle has been covered, and when the preliminary counts have been done, it is time to place the sternal wires. The first wires are usually placed in the manubrium, with at least two, or, perhaps preferably, three, wires being placed here. Occasionally, especially in younger, healthy patients, the bone is too hard to drive the needle of a sternal wire through it. While one can 'choke up' on the needle to aid in getting the wires through tough bone, another solution to that problem can be to use a drill which can bore through the manubrium. One small tip here is to put the wire through each hole as it is drilled, because it can be hard to find the hole you have drilled, if you take your eye off of it, even briefly. Sometimes a fine forceps or similar tool can be placed in the hole to facilitate seeing where the wire needs to be placed.

Next, the lower wires are placed in the rest of the sternum. There are many different strategies employed for these wires. If simple, interrupted wires are used, one can consider putting in as few as eight wires (counting two in the manubrium) or as many as twelve. [Tector, 1996]. Putting in extra wires is attractive if the sternum seems narrow or osteoporotic or if both internal mammary arteries have been taken down, especially if they were not taken down in a skeletonized manner.

When placing interrupted sternal wires in the sternum, inferior to the manubrium, one can also choose between placing them through the sternum, around the sternum in the interspaces, or both. Placing them around the sternum is particularly attractive if the sternum is narrow or seems osteoporotic. Since the intercostal vessels tend to run on the upper side of the interspaces ('hanging from' the lower edge of the ribs, as we all learned in gross anatomy in medical school), it seems judicious to place any wires that will encircle the sternum in the lower part of each interspace.

I personally have never liked wires placed in a figure of eight fashion, though there are thoughtful surgeons who swear by them. My own reservation about wires placed in this manner is that I have always found it hard to snug them up as well as I would like. Furthermore, when wiring patterns have been studied in cadavers, the figure of eight wiring pattern has been demonstrated to be not as secure as interrupted wires.[Dasika, 2003] 

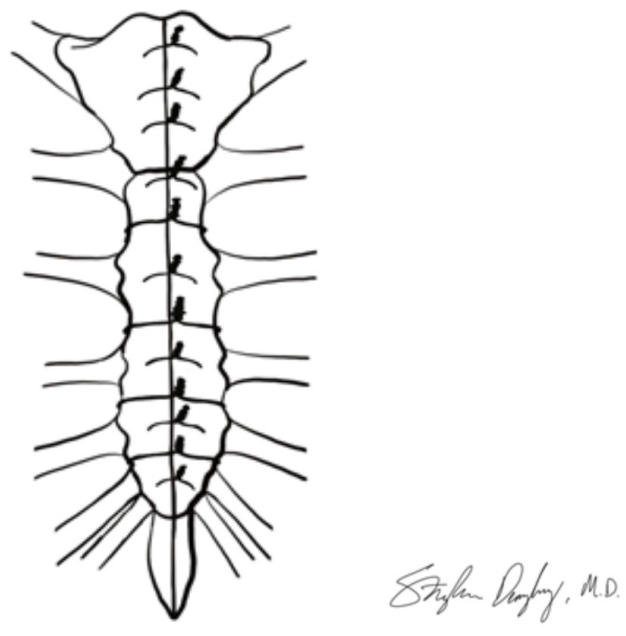

If I am particularly worried about the sternal closure, such as in patients with osteoporotic bone, in muscular, healthy patients, or, perhaps, in those in which bilateral internal mammary arteries have been harvested, I have used more wires, often putting in as many as 12 , alternating between placing them through the sternum and around the sternum in the interspaces. [Losanoff 2004]

After all the sternal wires have been placed, the underside of both sides of the sternum must be inspected to ensure that none of these wires has caused bleeding by penetrating a vessel. If this type of bleeding is detected, a figure of eight stitch of absorbable suture can be placed around the wire, which will usually control the bleeding. It is occasionally necessary to take that sternal wire out and place another one after the bleeding is controlled. Removing a wire that has 'skewered' a vessel will usually stop the bleeding, especially if pressure is held on the site.

When hemostasis has been assured, all tubes and pacing wires positioned, and the preliminary counts have been completed, the wires are pulled up and twisted. The optimal way to do this is to pull the wires straight up towards the ceiling and to allow the needle holder to descend passively as the wire is twisted. However, it is essential not to over-tighten these wires, as doing so will weaken the wires. In fact, when you see broken sternal wires on postoperative chest $\mathrm{X}$-rays, you will know that the surgeon overtightened those wires. Period. Rather, you need to rely on the rest of your closure to supplement the wires, as we will discuss below. After completing the twisting of the sternal wires, the twisted portion should be turned so that they align with the wires themselves, to allow the spaces between the wires to be free for the subsequent placement of supplemental sutures. The tips of the twisted portions of the wires should also be pushed down into the soft tissue to the side of the midline. This maneuver will help assure that these wire tips will not poke out into the skin of the middle of the chest. When you hear a patient complaining about the wires bugging them after they have healed up, it is because someone failed to manage the tips of the twisted wires appropriately.

Although there has been a lot of attention given to using sternal plating in recent literature, many surgeons, myself included, do not think that this strategy adds much, if any benefit to an otherwise well closed sternum. And, these plates have the disadvantages of taking extra time to insert and of adding to the difficulty of rapid re-entry, should that become necessary. [Pinotti, 2018, Tugulan 2020]

\section{THE MOST IMPORTANT PART OF THE STERNAL CLOSURE, PART II}

Since the strength of the chain is determined by the weakest link, then the first step to improve an organization must be to identify the weakest link. -Eliyahu M. Goldratt, Theory of Constraints [Goldratt, 2017]

The next stage of closing the sternotomy is the most important, and it is simple. First, however, an anatomy lesson is in order. As we all learned early in anatomy class in the first year of medical school, the fascia of the body wall is continuous. Stop for a moment and ponder that fact. This fascia is not only continuous around the trunk, it is also continuous from the neck to the groins. That fact is obvious to anyone who has closed a midline abdominal incision, but this concept seems to be lost on many, if not most, who close median sternotomy incisions.

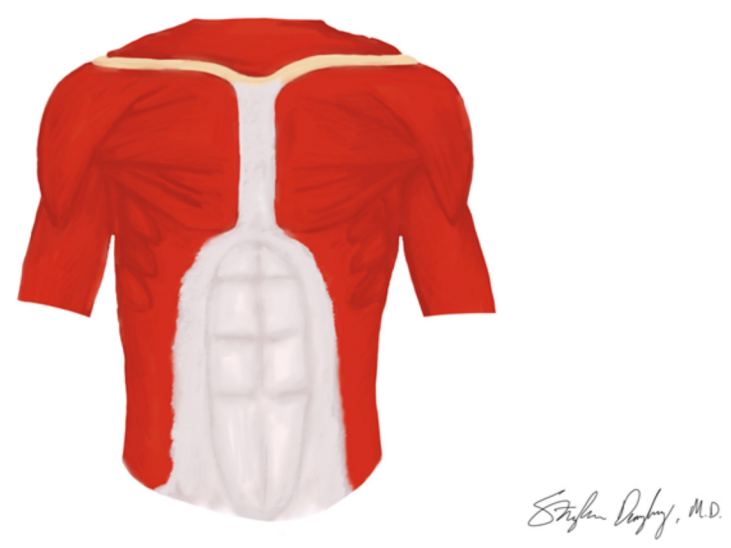

Now, it is important to note that the fascia of the anterior chest wall, becomes adherent to the periosteum of the sternum near the midline. Therefore, to close this layer, as one must when closing a sternotomy, strong sutures must be placed in it. I like to say to residents learning to close a sternotomy that they should envision the sternum itself to be analogous to the peritoneum, providing little, if any, of the strength of the closure of the respective body cavities. That exaggeration is offered to make the point that this layer of tissue must be closed securely, in addition to approximating the bone of the sternum.

In fact, it has long been known, though not widely understood, that the anterior chest wall can be closed in an effective and stable manner without closing the sternum at all. I first learned about this important concept through reports from the 
Cardiac Surgery and Plastic Surgery groups at the Columbia Presbyterian Hospital (now known as the New York Presbyterian Hospital), in which they reported treating sternal infection, or even sternal instability, by leaving the sternum 'open' and freeing up the pectoral muscles from the sternal edges far enough laterally to allow these muscles to be reapproximated in the midline. They found that this strategy worked well, not only for sternal instability but also for sternal infections. [Jeevanadum, 1990]. This group's experience with this successful strategy was recently updated. [Levy, 2019] I have myself used this approach in a variety of circumstances and found it to be very straightforward and effective. In essence, given that this approach works well even in more complex situations, it follows that taking advantage of these principles in routine cases seems imminently reasonable as well.

In more routine cases, all of these fascial / periosteal sutures should be placed in an interrupted manner, as a running suture will, inevitably, loosen and, therefore, lose its effectiveness. Heavy braided absorbable suture seems preferable for these sutures, because it ties more securely and because the cut ends will lie flat in the base of the wound. I will note, however, that some surgeons like monofilament suture better because it is thought to be a bit more resistant to infection, which may be a valid consideration. I like to start at the top of the chest, with my first stitches digging into the base of the strap muscles of the neck as they insert on the top of the manubrium. As an aside, one should avoid pulling the strap muscles themselves together in this area, as they were never in the midline and pulling them together can cause a 'lump' in the lower neck, which can be a bit unsightly. Next, I place at least one figure of eight suture between each of the sternal wires, with each needle digging into the periosteum of the sternum. If the distance between wires permits, I will put two of these sutures between wires. As you work your way down the sternum, you will eventually get to the 'no man's land' area around the xiphoid. I call this area 'no man's land' because the fascia of the lower chest and of the upper abdomen often seems to 'splay out' a bit. I suspect that this somewhat weaker area is the reason that a running suture sometimes loosens in this area, which can jeopardize the whole closure. I will note, again, that the solid fascia of the upper abdominal midline should have already had interrupted figure of eight sutures placed in it, and, if those sutures have not been placed already, they should be placed at this point. With all of these sutures being placed in an interrupted fashion, the weaker area of the 'no man's land' around the xiphoid will have a minimal effect on the integrity of the overall fascial closure.

\section{CLOSING THE SOFT TISSUES OF THE CHEST} WALL (TO AVOID A SUCKING CHEST WOUND)

It's long been an axiom of mine that the little things are infinitely the most important. - Sir Arthur Conan Doyle, in Sherlock Homes: A Case of Identity

Once all of the fascial sutures have been placed, and tied, you are ready to turn your attention to the closure of soft tissues and skin of the chest and upper abdomen. It cannot be over-emphasized that the overall chest closure must be airtight, as well as water tight. You must do everything imaginable to avoid leaving a 'sucking chest wound.' [Lewis, 1982] After all, the chest is the only negative pressure cavity in the body. Any air that is sucked into the wound will, undoubtedly, carry bacteria from the skin into the soft tissues. Furthermore, if fluid is leaking out, at any point, air is, most assuredly, being sucked into the wound and, likely, into the mediastinum.

It is also important to recognize that the ephemeral (possibly mythical) layers of so-called fascia in the soft tissues between the 'real' fascia and the skin play no role, whatsoever, in closing the soft tissues of the anterior chest wall. For Trivial Pursuit or Jeopardy enthusiasts, these mythical layers are called by anatomists 'Camper's' and 'Scarpa's' fascia. The rest of us can forget about these entities, as they have about the same substance as moonbeams and flatus. Sutures placed in the soft tissues of the chest between the deep fascia and the skin will do nothing more than cause fat necrosis, which is counterproductive to optimal healing of this wound and may increase the risk of infection.

What, then, should you do about this space (which can be considerable in obese people)? This space is managed optimally with drains, such as Jackson Pratt or small Blake drains, which should be led out of the skin of the lower chest. These drains will not only evacuate fluid and residual air from this space, but they will also create enough suction to pull the fatty soft tissues together, minimizing or eliminating the potential space in which fluid might accumulate, and they will, therefore, promote the rapid healing of the skin. These drains should remain in place until there is no longer any fluid accumulating in the suction bulbs or canisters.

The next step of the closure is to approximate the skin with deep dermal stitches using absorbable sutures, usually something like 3-0 Vicryl. The final layer should be a subcuticular stitch, with 4-0 undyed Vicryl or Dexon suture. If the skin is too thin to suture easily, as is sometimes the case in the elderly, or if the skin is scarred, as may be true in a reoperative case, the skin can be stapled. The primary downside to using staples is that they take more time to remove, if an emergent re-entry to the chest is required postoperatively. And, a secondary downside to staples is that they will, of course, need to be removed at some point, which can be inconvenient for all concerned. Furthermore, the healed wound is not as cosmetically appealing as when a subcuticular closure is used. And, it's worth noting again that the skin closure must be air tight.

The final step in closing the skin is to coat the wound with antibiotic ointment or Dermabond, either of which will help seal the skin and will also promote rapid, optimal healing. This strategy has been shown to reduce mediastinitis rates to a surprising degree. [MacIver, 2005 \& Chan, 2017] Many cardiac surgeons also use a Prevena dressing, which not only supports the wound edges but also creates a negative pressure environment, which some authors have shown can reduce infections. This device seems particularly attractive for obese patients. [Dohman, 2014]

If the patient has any amount of breast tissue beyond minimal, the weight of the breasts must be taken off of this sternal 
skin closure. A straightforward approach to this issue can be to have the patient bring in one of their own bras from home to wear, around the clock, after their operation. (Patients will appreciate being informed that this bra will likely be destined for disposal after it has served its purpose, because it will almost certainly end up stained and discolored.) Another option for taking the pressure of breasts off of the midline skin incision is to use what Plastic Surgeons call an "Ioban Bra." Plastic Surgeons who perform breast reduction surgery know that they, too, need to protect the skin incisions needed for these operations in the early postoperative period, and these surgeons commonly use these sticky drapes for this purpose. To be even more specific, they hold the breasts together, near the midline of the chest, and apply the sticky drape so that it covers almost all of both breasts, which effectively takes virtually all stress off of the sutures lines.

A final note about the incisions made during cardiac surgery pertains to the chest tube exit sites. First of all, the skin incisions made for the exit sites of mediastinal tubes should, most certainly, be horizontal and not vertical. The reason for this orientation of these incisions is that, when the patient sits up once the tubes have been removed, as the anterior abdominal wall 'wrinkles,' these incisions will be pressed together in a way that promotes sealing and healing. Chest tube site incisions made so that they parallel the midline will tend to gap open when the patient sits up. Some surgeons also place sutures in or near the middle of these incisions and leave those sutures untied, planning to tie them as these tubes are removed. However, many surgeons do not use this technique, especially if the chest drains used are smaller bore tubes, such as Blake drains.

\section{POSTOPERATIVE CARE OF THE STERNAL SKIN INCISION}

The first, and most important, principle of caring for the sternal incision after the operation is that any amount of fluid that is leaking from the wound, at least more than a drop or two, should be a cause for considerable concern because, as noted earlier, if fluid is coming out, it is virtually certain that air is being sucked into the wound, likely carrying bacteria from the wound edges into the wound.

One option for dealing with a fluid leak from a sternal wound might be to place a Prevena device over the wound. However, one must acknowledge that the wound is likely no longer sterile, and, therefore, the Prevena dressing may trap bacteria in or on the wound under such circumstances. However, one can consider prepping the incision itself with a germicidal solution prior to placing a Prevena device postoperatively.

If more than a small amount of fluid is leaking, you should consider taking the patient back to the operating room and reclosing the sternal incision. If this approach is taken, you should place a suction drain in the soft tissues between the sternum and the skin, after thoroughly irrigating the wound, preferably with a suction / irrigation device. Furthermore, some would recommend that any wound that has been reopened be treated with vacuum-assisted therapy. [Hersh, 2001]

When the skin edges of the sternal closure do seem to have become adherent, it is not unreasonable to take the dressing off of the wound and leave it 'open to air.' However, the wound must be closely watched and should, in most cases, be cleaned daily with an antiseptic solution and then recoated with antibiotic ointment.

Again, for patients with significant soft tissue on the anterior chest wall, especially women with large breasts, some type of continued support of this tissue is imperative. For those with large breasts, a bra should be worn at all times, day and night, except when showering, for at least a week or two after they have been discharged. One should include in the discharge instructions, the need to report any more than a few drops of fluid emanating from the wound.

Once the skin edges have sealed there is no longer any value to keeping a dressing on the wound. In fact, these dressings can, occasionally, hinder recovery, at least partly by being a bit restrictive, pulling on the skin of the chest which can injure the skin, at least superficially. Furthermore, patients whose superficial wounds seem to be healing properly can be allowed to shower (though it does seem prudent to have them avoid taking baths in tubs, both because soaking in a tub might interfere with the sealing of the wound and because getting into and out of tub runs the risk of putting too much pressure on the sternum itself).

Finally, some patients will ask about putting some kind of unction or another on the wound, usually thinking that some substance of this sort will make the cosmetic outcome more to their liking. The most common substance asked about in this context is Vitamin E cream. I have no reason to suspect that such a cream would be either harmful or beneficial, so I generally give my 'blessing' to such ointments or salves.

\section{POSTOP PAIN MANAGEMENT}

There has been an increasing, and appropriate, emphasis on minimizing the use of opiates for postoperative pain control in many types of operations. Most patients who have had a sternotomy can be kept comfortable with the use of acetaminophen and non-steroidal agents. [Engelman, 2019]

Although a wide array of pillows, vests, and other devices have been used in hopes of minimizing discomfort in patients who have had a sternotomy, it has been hard to demonstrate much, if any, value to their use. Still, there may be at least a bit of psychological value to employing these strategies. At the very least, it can be fun to sign the patients' pillows, if asked to do so. My favorite note to write on these pillows is 'we have to stop meeting like this!'

\section{RESTRICTIONS AFTER STERNOTOMY}

The force across the sternum during a cough was 60 pounds, or greater than the force exerted while lifting two 20-lb weights simultaneously. [Adams, 2016]

There are about as many protocols for activity restriction after a median sternotomy as there are practitioners who 
prescribe them. I have heard surgeons tell their patients that they cannot even brush their hair for a month postoperatively. In my opinion, these kind of restrictions are not only unnecessary, but they can also significantly interfere with overall postoperative recovery. If the sternum has been opened and closed properly, the recovering patient can be allowed to do quite a bit more than just brush their hair.

I have always told my patients that they can do anything that does not entail putting more pressure on the arms, and, therefore, the chest, than would be created by lifting 10 pounds with one arm. I explain this limitation by noting that a gallon of milk weighs eight pounds, which almost everyone understands. Furthermore, to extend this advice, I suggest that patients obtain two empty gallon jugs to have at home when they return there. Obviously, when following my regimen, they can move those jugs, when empty, around as much as they want. I tell them to gradually add water to the jugs, a bit at time, aiming to have them full by about the third or fourth week after they go home. I have yet to meet a patient or family who does not understand this advice. I always point out to them that the further away from the trunk they hold these jugs, the more pressure there will be on the healing sternum. Therefore, I suggest that they start moving their jugs around with their arms close to the chest and then, gradually, extending their arms out more and more over the ensuing weeks. This strategy has been effective and safe for virtually all patients, unless there were some extenuating circumstances, such as some kind of early postoperative problem with the wound. Again, it is worth noting that a strong cough or a sneeze has been shown to put as much pressure on a healing sternum as lifting two 20 pound weights simultaneously with both hands. [Ley, 2019]

A slightly different way to describe reasonable sternal precautions has been developed by a team of physical therapists at Baylor University Medical Center, which they colorfully describe as the 'Move in the Tube' precautions. This approach recommends keeping the upper arms close to the chest, so that there is less leverage on the sternum while using the hands for 'activities of daily living' like getting out of bed, opening a door, or rising from a chair or toilet. The time line for loosening these restrictions should be modified by factors such as age, nutritional status, or, perhaps, the degree of osteoporosis of the sternum observed during the operation. In addition to these prescribed limits, the patients can also make their own observations, such as what they can do without discomfort. [Adams, 2016]

Patients will often be given a surprising array of additional restrictions, particularly when it comes to riding in a car. First of all, the patients should not drive a car for a finite time. This admonition is more of a legal one and should be thought about in terms of degree of alertness, pain medication usage, and other considerations. My own practice has been to say that they should not drive a car until I see them back in my office for their four week postop visit. You have to be careful in your admonitions, however. I once had a patient fly his own plane back to his postop clinic visit, wryly telling me that I had told him not drive but had not told him not to fly! One specific restriction often imposed inappropriately is to not wear a seat belt when riding in a car, or at least not one with a shoulder belt. That advice is just plain inappropriate. A properly worn seat belt will be far better for such a patient, should a car crash occur, than to have them slam into the dashboard of the car. Another bit of inappropriate advice is to tell a patient with a healing sternotomy that they must ride in the back seat of a car. Once again, that restriction is simply unnecessary. Similarly, admonishing patients not to ride in a seat with an air bag that would deploy in an accident is unnecessary. Such an air bag deployment will not hurt the healing sternum, while slamming into the dashboard might.

Perhaps the most interesting questions I have had patients ask, especially those who live in the rural areas near where I have worked most of my professional life, is when they can go hunting after their operations. I figured that they could go outside with their hunting pals and even shoot a low caliber rifle, such as a 22 caliber rifle, but that they should not shoot a shotgun or high powered rifle for about six weeks. My patients who were hunters have seemed to find that restriction not to be overly burdensome.

In fact, I have never had a patient, whose sternum was properly closed, experience a 'late' dehiscence of their sternal closure, with the exception of several extreme and very unusual cases. One of these cases involved a patient who, while out hunting with his friends, was sitting on a dog box in the back of a pickup truck when the driver, not realizing his pal was sitting there, cranked up the truck and pulled out of the spot in which it was parked. My patient fell backwards, landing on his shoulders after what must have been a 5 or 6 foot fall. We had to reclose his sternum. Another case involved a young man who had been allowed to start driving about six weeks after his operation and who was involved in a head on collision a few weeks later, with both cars going about 45 miles per hour. Everyone in both cars, other than my patient, died at the scene. We had to reclose that patient's sternum as well, though he recovered quickly.

\section{SUMMARY}

Sometimes the questions are complicated and the answers are simple. -Dr. Seuss

Even though the median sternotomy incision is a very commonly performed procedure, many of the important details and nuances of this technique are not uniformly taught to surgical trainees. Thus, we have attempted to outline the key principles in using this incision, closing it properly, and caring for patients who have had this incision as they recover.

The primary goal of all of the strategies discussed is, obviously, to have a sternal closure that is stable and that will heal well. However, these same strategies will also reduce the incidence of mediastinitis, the management of which, it is worth noting, is no longer reimbursed by The Centers for Medicare and Medicaid Services when this conditions arises as a complication of coronary artery bypass operations. [Stone, 2010]. 


\section{REFERENCES}

Tribble C. Reoperative Cardiac Surgery: Part I - Preoperative Planning. The Heart Surgery Forum 2018; 21: E63-9

Tribble C. Reoperative Cardiac Surgery: Part II. The Heart Surgery Forum 2018; 21: E124-131.

Julian O, Lopez-Belio M, Dye W, Javid H, Grove W. The median sternal incision. Surgery 1957; 42: 753-61.

Dalton M, Connally S, Sealy W. Julian's Reintroduction of Milton's Operation. Ann Thorac Surg 1992; 53: 532-3.

Edwards F, Engelman R, Houck P, Shahian D, Bridges C. The STS Practice Guideline Series: Prophylaxis in Cardiac Surgery. 2006; 81: 397-404.

Hong J, Saraswat M, Ellison T, Magruder J, Crawford T, Gardner, J, Padula W, Whitman G. Staphylococcus Aureus Prevention Strategies in Cardiac Surgery: A Cost-Effectiveness Analysis. Ann Thorac Surg 2018; 105: 47-53.

Lazar H, McDonald M, Chipkin S, Furnary A, et al. The Society of Thoracic Surgeons Practice Guideline Series: Blood Glucose Management during Adult Cardiac Surgery. Ann Thorac Surg 2009; 87: 663-9.

Tribble C, Merrill W. The Way We Talk is the Way We Teach. J Thorac Cardiovasc Surg. 2014; 147: 1155-9.

Lee ME, Blanche Carlos. Curvilinear Paramedian Sternotomy. Ann Thorac Surg 1984; 38: 414.

Williams CD. Curved Sternotomy Incision. Tex Heart Inst J; 2000: 27: 419.

Lazar $H$. The use of vancomycin paste to reduce sternal wound infections after cardiac surgery - why is this still a "sticky" subject? J Thorac Cardiovasc Surg. October 2017; 154: 1324-5.

Vestergaard R, Jensen H, Vind-Kezunovic S, Jakobsen T, Søballe K, Hasenkam J. Bone healing after median sternotomy: A comparison of two hemostatic devices. J Cardiothorac Surg 2010; 5: 17-27.

Wellisz T, Armstrong J, Cambridge J, Wen X, Hill C, Fisher T. The Effects of a Soluble Polymer and Bone Wax on Sternal Healing in an Animal Model. Ann Thorac Surg 2008; 85: 1776-80.

Flege J. Pericardial incision for internal mammary artery coronary bypass. Ann Thorac Surg 1987; 44: 424.

Tribble C. The Skeleton in the Closet: Harvesting a Skeletonized IMA. The Heart Surgery Forum 2017; 20: E178-83.

Kalso E, Mennander S, Tasmuth T, Nilsson E. Chronic Post-sternotomy Pain. Acta Anaesthesiologica Scandinavia 2001; 45: 935-9.

Khonsari S, Sintek C. Cardiac Surgery: Safeguards and Pitfalls in Operative Technique. 4th Edition. 2007. Lippincott Williams \& Wilkins. Philadelphia, PA.

Loor G, Vivacqua A, Sabik J, Li L, Hixson E, Blackstone E, Koch C. Process improvement in cardiac surgery: Development and implementation of a reoperation for bleeding checklist. J Thorac Cardiovasc Surg 2013; 146: 1028-32.

Dasika U, Trumble D, Magovern J. Lower Sternal Reinforcement Improves the Stability of Sternal Closure. Ann Thorac Surg 2003; 75: 1618-21.

Tector AJ, Cress DC, Downey FX, Schmahl TM. Use of internal
Thoracic artery T-Grafts for complete arterial revascularization. Op techniques in cardiac and thoracic surgery 1996; 1:108-116.

Losanoff J, Collier A, Wagner-Mann C, Richman B, Huff H, Hsieh F, Diaz-Arias A, Jones J. Biomechanical Comparison of Median Sternotomy Closures. Ann Thorac Surg 2004; 77: 203-9.

Pinotti K, Cataneo D, Rodrigues O, Cataneo A. Closure of the sternum with anchoring of the steel wires: systematic review and meta-analysis.

J Thorac Cardiovasc Surg 2018; 155: 177-86.

Tugulan CI, Spindel SM, Bansal AD, Bates MJ, Parrino EP. Does Elective Sternal Plating in Morbidly Obese Patients Reduce Sternal Complication Rates? Ann Thorac Surg 2020; 110:1898-903

Goldratt E. The Goal, Introduction to the Theory of Constraints. 2017. The North River Press Publishing Corporation. Great Barrington, MA

Jeevanandam V, Smith CR, Rose EA, Malm JR, Hugo NE. Single-stage management of sternal wound infections. J Thorac Cardiovasc Surg 1990; 99: 256-62.

Levy A, Ascherman J. Sternal Wound Reconstruction made Simple. Plast Reconstr Surg Glob Open. 2019; 7: e2488.

Lewis F. Thoracic Trauma. 1982. Surg Clinics North America 62: 97-104.

MacIver R, Stuart R, Fredrickson J, Fullerton D, Horvath K. Topical Application of Bacitracin Ointment is Associated with Decreased Risk of Mediastinitis after Median Sternotomy. The Heart Surgery Forum 2006; 9 (5): $\mathrm{E} 750-3$.

Chan J, Diaconescu A, Horvath K. Routine use of topical bacitracin to prevent sternal wound infections after cardiac surgery. Ann Thorac Surg 2017; 104: 1496-500.

Dohman P, Markou T, Ingemansson R, Rotering H, Hartman J, van Valen R, Brunott M, Segers P. Use of Incisional Negative Pressure Wound Therapy on Closed Median Sternal Incisions after Cardiothoracic Surgery: Clinical Evidence and Consensus Recommendations. Med Sci Monit 2014; 20: 1814-25.

Hersh R, Kaza A, Long S, Fiser S, Drake D, Tribble C. A technique for the treatment of sternal infections using the Vacuum Assisted Closure device. Heart Surg Forum 2001; 4: 211-5.

Engelman D, Ali W, Williams J, Perrault L, Reddy S, Arora R, Roselli E, Khoynezhad A, Gerdish M, Levy J, Lobdell K, Fletcher N, Kirsch M, Nelson G, Engelman R, Gregory A, Boyle E. Guidelines for Perioperative Care in Cardiac Surgery: Enhanced Recovery After Surgery Society Recommendations. JAMA Surg 2019; 154: 755-66.

Adams J, Lotshaw A, Exum E, et al. An alternative approach to prescribing sternal precautions after median sternotomy, "Keep Your Move in the Tube". Proc (Bayl Univ Med Cent). 2016; 29: 97-100.

Ley J, El-Ansary, Mohd K, Adams J, Triano S, Gach R. Goodbye Sternal Precautions, Hello Move in the Tube. CTS NET (https://www.ctsnet. org), 4-18-2019.

Stone P, Glied S, McNair P et al. CMS changes in reimbursement for HAIs. Med Care 2010; 48: 433-9. 